\title{
Rosai-Dorfman disease with renal involvement and associated autoimmune haemolytic anaemia in a 12-year-old girl: $A$ case report
}

\author{
Tharmini Danisious $^{1 *}$ (D), Mathula Hettiarachchi ${ }^{2}$, Chanuka Dharmadasa ${ }^{2}$ and Heshan Jayaweera ${ }^{1}$
}

\begin{abstract}
Background: Rosai- Dorfman Disease (RDD) is a benign condition of unknown aetiology which is characterized by non-neoplastic proliferation of histiocytes. Pathophysiology and natural history remain obscure due to the low prevalence of disease. It is known to present with nodal or extranodal involvement and occurrence in the genitourinary system could lead to dreadful complications. RDD is diagnosed by demonstrating emperipolesis on histology and supported by $\mathbf{S 1 0 0}$ positivity in immunohistochemistry. Treatment is tailored individually and includes expectant monitoring, steroids, surgery, chemotherapy and radiotherapy. Prognosis will be poor if there is involvement of vital organs. We report a rare case of renal Rosai-Dorfman Disease in a 12-year-old girl which also associated with cold type autoimmune haemolytic anaemia (AlHA).

Case presentation: A previously healthy, 12-year-old girl presented with low grade fever and cough over one month. On examination, she was pale, mildly icteric and had a firm mass in the left hypochondrial region. Her blood count revealed significant eosinophilia, normocytic normochromic anaemia and thrombocytosis. Further laboratory investigations revealed reticulocytosis, positive urine urobilinogen, positive direct antiglobulin test and red blood cell agglutination on blood picture suggestive of autoimmune haemolytic anaemia. Ultrasound scan of abdomen revealed paraaortic and left side retroperitoneal lymphadenopathy with left renal mass. It was further evaluated by Contrast Enhanced Computed Tomography (CECT). Biopsy was done and that concluded sinus histiocytosis with massive lymphadenopathy (SHML) with positive S100 and CD1a in immunohistochemistry. Child was treated with steroids however there was no significant response as assessed by repeat $C T$ and has been commenced on chemotherapy.
\end{abstract}

Conclusion: RDD is believed to be due to host immune dysregulation and precise diagnosis is imperative. It should be considered as differential diagnosis in a child presenting with massive lymphadenopathy and AlHA. Association between RDD and AlHA may possibly be explained by abnormal immune response of the host.

Keywords: Renal Rosai-Dorfman, Sinus histiocytosis, Autoimmune haemolytic anaemia, Child, Case report

\footnotetext{
* Correspondence: dtharmini18@gmail.com

1 Professorial Paediatric Unit, Teaching Hospital, Peradeniya, Sri Lanka

Full list of author information is available at the end of the article
}

(c) The Author(s). 2020 Open Access This article is licensed under a Creative Commons Attribution 4.0 International License, which permits use, sharing, adaptation, distribution and reproduction in any medium or format, as long as you give appropriate credit to the original author(s) and the source, provide a link to the Creative Commons licence, and indicate if changes were made. The images or other third party material in this article are included in the article's Creative Commons licence, unless indicated otherwise in a credit line to the material. If material is not included in the article's Creative Commons licence and your intended use is not permitted by statutory regulation or exceeds the permitted use, you will need to obtain permission directly from the copyright holder. To view a copy of this licence, visit http://creativecommons.org/licenses/by/4.0/ The Creative Commons Public Domain Dedication waiver (http://creativecommons.org/publicdomain/zero/1.0/) applies to the data made available in this article, unless otherwise stated in a credit line to the data. 


\section{Background}

Sinus histiocytosis with massive lymphadenopathy (SHML), also known as Rosai- Dorfman Disease (RDD) is a benign self-limiting condition of unknown etiology which is characterized by non-neoplastic proliferation of histiocytes in the sinusoids of lymph nodes and in extra nodal tissues [1]. It has a prevalence of 1 in 200,000 [2]. It commonly occurs in the second and third decades of life $[3,4]$. Pathophysiology and natural history remain concealed due to the low prevalence of disease. Postulated aetiologies include an exacerbated immune response to infections such as Epstein- Barr virus (EBV), Cytomegalovirus (CMV), Brucella, Klebsiella [5], human herpesvirus-6 (HHV-6) [6], or an autoimmune disease or a neoplastic process [7-10].

Diagnosis is established by demonstrating emperipolesis in histology and S100 positivity in immunohistochemistry [10-12]. Although no standard treatment has been established in children, it is tailored depending on the clinical presentation and involvement of vital organs. Expectant monitoring, steroids, surgery, chemotherapy and radiotherapy have been attempted with variable clinical response. We present a rare case of renal RosaiDorfman Disease associated with cold type autoimmune haemolytic anaemia (AIHA) which has not been previously described in the paediatric population.

\section{Case presentation}

A previously healthy, 12-year-old girl presented with low grade fever of one-month duration associated with a nonproductive cough. She did not have night sweats. On examination, she was afebrile, pale and icteric without significant lymphadenopathy. Her abdominal examination revealed a firm mass on the left hypochondriac region. Other system examinations including musculoskeletal and neurological examination were unremarkable.

Her initial blood count revealed normal white cell count with significant eosinophilia (11\%), normocytic normochromic anaemia $(6.3 \mathrm{~g} / \mathrm{dl})$ and thrombocytosis $\left(533 \times 10^{\wedge} 3 / \mathrm{uL}\right)$. Further investigations revealed reticulocytosis $(6.58 \%)$, positive urine urobilinogen and positive Direct Antiglobulin Test (DAT). Detailed DAT profile demonstrated negative IgG and positive C3d. Blood picture showed red blood cell agglutination, reticulocytosis with polychromasia and occasional spherocytes. With these findings, it was concluded as a cold type autoimmune haemolytic anaemia which was supported by elevated lactate dehydrogenase (LDH) level [LDH- $450 \mathrm{U} /$ $\mathrm{L}(120-330 \mathrm{U} / \mathrm{L})]$. She had elevated total $(27 \mu \mathrm{mol} / \mathrm{L})$ and direct $(17 \mu \mathrm{mol} / \mathrm{L})$ bilirubin levels, but the gammaglutamyl transferase (GGT) and alkaline phosphatase (ALP) were within the normal range.

Serum ferritin $(430 \mathrm{ng} / \mathrm{mL})$, erythrocyte sedimentation rate $(125 \mathrm{~mm} / 1$ st hour $)$ and C-reactive protein $(234 \mathrm{mg} / \mathrm{l})$ were elevated. Renal function tests and rest of the liver profile remained normal throughout the course of illness.

Concurrently, Ultrasound (US) scan of abdomen revealed a solitary mass confined to the left kidney with para aortic lymphadenopathy causing left ureteric compression and hydronephrosis. She was further investigated with CECT of chest and abdomen which concluded the same findings as in US scan [Fig. 1]. Primary tumor markers such as Alpha-fetoprotein (AFP) and Beta human chorionic gonadotropin ( $\beta$-hCG) were normal.

Suspecting possibility of haematological malignancy, bone marrow aspiration and trephine biopsy were undertaken and that too did not reveal any abnormal cells or evidence of bone marrow infiltration. US guided tru-cut biopsy of the retroperitoneal lymph node showed epithelioid looking cells in sinuses with reactive background of lymphoid tissue which was indecisive. Therefore, excisional biopsy of perihilar lymph node and a tru-cut biopsy from the renal mass were performed. The features of both biopsies were compatible with SHML with S100, CD68 and CD1a positivity in immunohistochemistry [Fig. 2].

Serum protein electrophoresis showed a polyclonal increase in gamma globulin without detection of any abnormal proteins. Her supplementary investigations showed hyperimmunoglobulinemia [IgG $2581 \mathrm{mg} / \mathrm{dl}$ (726-1085), IgA $338 \mathrm{mg} / \mathrm{dl}$ (70-229), IgM $130 \mathrm{mg} / \mathrm{dl}$ (35-72)] and hypoalbuminemia $(23.7 \mathrm{~g} / \mathrm{L})$. Viral serology for EBV and CMV were negative. Furthermore, Antinuclear antibodies (ANA) and rheumatoid factor (RF) were also negative.

She was treated with oral prednisolone for three months but there was no significant response as assessed by a repeat CT. Subsequently she was commenced on multidrug therapy consisting of mercaptopurine, methotrexate and vinblastine, however, she had marginal response to the therapy. She has been on regular follow-up to assess the progression of disease. Further treatment and followup will depend on her response to treatment.

\section{Discussion and conclusions \\ Discussion}

This rare disease entity was first described in 1965 by Rosai and Dorfman, however it was recognized as a clinical and pathological entity only after four years of its description [8].

Symptoms and physical findings depend on the organ involved and are widely variable. Lymphadenopathy being the main clinical manifestation and frequently involves cervical and submandibular regions. It can also affect axillary, inguinal and mediastinal regions. RDD significantly involves extra-nodal tissue (43\%) and may be associated with other forms of histiocytosis [1]. The common sites for extra nodal involvement are skin, upper respiratory tract and bone [7]. However, it can 


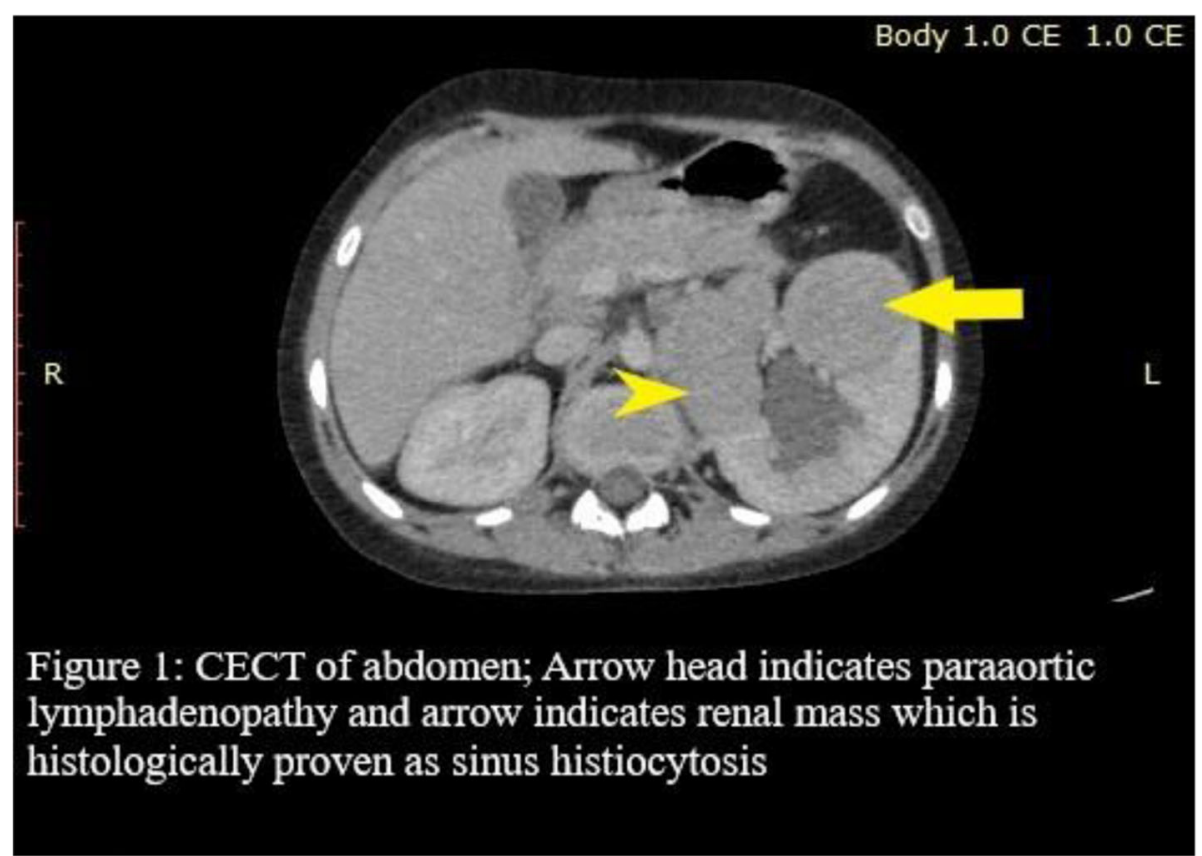

Fig. 1 CECT of abdomen; Arrowhead indicates paraaortic lymphadenopathy and arrow indicates renal mass which is histologically proven as sinus histiocytosis

occur in the genitourinary system, lower respiratory tract, oral cavity and soft tissues. Among the patients with extra-nodal involvement, approximately $75 \%$ have disease in head and neck region [13]. Involvement of lower respiratory tract, kidney or liver indicates poor prognosis [7].

In the literature, a 7-year old boy with diagnosis of RDD found to have renal involvement manifested as membranoproliferative glomerulonephritis during follow-up. He was treated with methylprednisolone and mizoribine and achieved complete remission [14]. Another study based on

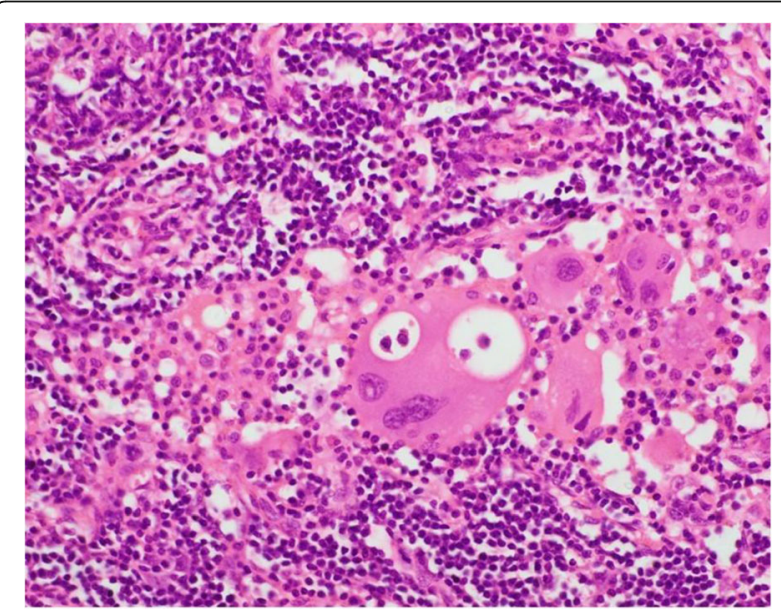

Fig. 2 Histiocytes demonstrating emperipolesis within a left side perihilar lymph node $(H \& E \times 400)$ a computerized case registry that evaluated 220 patients, revealed glomerulonephritis in three patients [15]. In our patient, histological diagnosis of sinus histiocytosis was made from the biopsy of renal mass and to the best of our knowledge this is the first case of renal RDD in a child.

Furthermore, our patient developed cold AIHA that warranted blood transfusion. Although haemolytic anemia is an infrequent complication, association of AIHA with RDD has been described in the past [18-20]. Etiology of RDD is unknown, yet it is considered to be due to immune dysregulation. Approximately $10 \%$ of patients with RDD had coexisting immunological disease such as AIHA and rheumatoid arthritis $(15,18)$. Up to 2018, only 4 paediatric cases of RDD associated with AIHA have been reported in the literature (20).

The practical difficulty in diagnosis is to distinguish RDD from sinus hyperplasia (sinus histiocytosis) due to the similarity in morphology, albeit well-defined expression of S100 protein in immunohistochemistry strongly associated with RosaiDorfman histiocytes and negative in normal sinus histiocytes [16]. Furthermore, Langerhans cell histiocytosis (LCH) is another differential diagnosis, characterized by clonal proliferation with different morphology to RDD and positive for both $\mathrm{S} 100$ and CD1a. In contrast, RDD is a $\mathrm{S} 100$ positive, CD1a negative histiocytes with emperipolesis of lymphocytes and other haematopoietic cells [17]. Occasionally, it may masquerade as lymphoma [3, 11]. 
Having a self-limiting course, RDD demands treatment for cases with pressure effects on vital organs [21]. Treatment options include expectant monitoring, steroids, chemotherapy and surgical excision with or without adjuvant radiotherapy [9]. High dose steroids exhibit response by a decline in lymph node size only during treatment while the use of methotrexate and 6mercaptopurine for complicated RDD show prolonged response subsequent to tailing off medications [22]. Place for rituximab has been described in a child who later manifested systemic lupus erythematosus (SLE) [23]. Prednisolone and vinblastine were trialed to treat RDD that co-occurred with LCH [24].

Surgery is shown to be effective in cases of isolated lymphadenopathy without vital organ involvement and $\mathrm{cu}-$ taneous or subcutaneous involvement [25]. Nevertheless, surgery can be disapproving in the latter due to the recurrent nature of the disease. In our patient, para-aortic and retroperitoneal lymphadenopathy was complicated with left hydronephrosis which will perhaps not be amenable to surgery or will have high risk due to surgery. Radiotherapy has shown to be effective in cutaneous RDD [25].

Irrespective of treatment, the prognosis of the disease is guarded with the reported fatality rate of $5-10 \%$ [26]. Regular long-term follow-up is indicated, and it includes assessing the progression of the disease, screening for concurrent diseases such as Sjogren syndrome, antiphospholipid syndrome and non-Hodgkin lymphoma [23, 25] and assessing the response for treatment.

\section{Conclusion}

RDD is believed to be due to host immune dysregulation and precise diagnosis is imperative as it can mimic malignant lymphoproliferative disorders in children. However, it is more challenging due to the rarity of the disease, absence of significant symptoms related to the disease, involvement of multiple sites and non-specific findings on images. It should be considered as differential diagnosis in a child presenting with massive lymphadenopathy and AIHA. Association between RDD and AIHA may possibly be explained by abnormal immune response of the host.

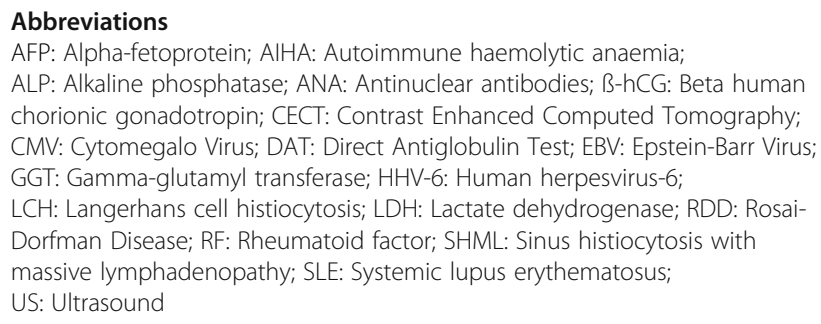

\section{Acknowledgements}

We all express our gratitude to the patient and parents who gave consent for this case to be presented in this paper. We also appreciate Dr. Mahendra Somathilaka, Consultant Paediatric Oncologist, National Cancer Institute, Maharagama, Sri Lanka for providing shared care in further follow up.

\section{Authors' contributions}

$\mathrm{TD}, \mathrm{MH}, \mathrm{CD}$ and $\mathrm{HJ}$ were responsible for delivering patient care. TD wrote the case and manuscript. Editing and supervision were done by $\mathrm{MH}, \mathrm{CD}$ and HJ. All authors revised and approved the final manuscript.

\author{
Authors' information \\ Tharmini Danisious, \\ Registrar in Paediatrics, \\ Professorial Paediatric Unit, Teaching Hospital, Peradeniya, Sri Lanka. \\ Mathula Hettiarachchi, \\ Consultant Paediatric surgeon, \\ Sirimavo Bandaranaike Specialized Children's Hospital, Peradeniya, Sri Lanka. \\ Chanuka Dharmadasa, \\ Consultant Histopathologist, \\ Sirimavo Bandaranaike Specialized Children's Hospital, Peradeniya, Sri Lanka. \\ Heshan Jayaweera, \\ Consultant Paediatrician, \\ Professorial Paediatric Unit, Teaching Hospital, Peradeniya, Sri Lanka. \\ Corresponding author. \\ Tharmini Danisious, \\ Registrar in Paediatrics, \\ Professorial Paediatric Unit, Teaching Hospital, Peradeniya, Sri Lanka. \\ dtharmini18@gmail.com \\ ORCID id https://orcid.org/0000-0002-4736-1140
}

\section{Funding}

No funding or grant support.

\section{Availability of data and materials}

The relevant data and materials are available at the hospital in case if needed. Corresponding author can be contacted to find out the details regarding this case. The permission should be also obtained from the director of the hospital for accessing the data.

Ethics approval and consent to participate

Not applicable.

\section{Consent for publication}

Written, informed consent was obtained from the parent of the patient for publication of this case report and accompanying images. A copy of the consent form is available for review.

\section{Competing interests}

The authors declare that they have no competing interests.

\section{Author details}

${ }^{1}$ Professorial Paediatric Unit, Teaching Hospital, Peradeniya, Sri Lanka.

${ }^{2}$ Sirimavo Bandaranaike Specialized Children's Hospital, Peradeniya, Sri Lanka.

Received: 28 April 2020 Accepted: 30 September 2020

Published online: 08 October 2020

\section{References}

1. Lima FB, Barcelos PS, Constâncio AP, Nogueira CD, Melo-Filho AA. RosaiDorfman disease with spontaneous resolution: case report of a child. Rev Bras Hematol Hemoter. 2011;33(4):312-4.

2. Mahzoni P, Zavareh MH, Bagheri M, Hani N, Moqtader B. Intracranial RosaiDorfman disease. J Res Med Sci. 2012;17(3):304.

3. Kishore M, Gupta P, Ahuja A, Bhardwaj M. Cytodiagnosis of Rosai-Dorfman disease masquerading as lymphoma: a case report with brief review of literature. J Lab Phys. 2018;10(4):460.

4. Hussain A, Tandon A, Prayaga AK, Paul TR, Narendra AM. Cytomorphology and histology correlation of Rosai-Dorfman disease: a 15-year study from a tertiary referral Centre in South India. Acta Cytol. 2017;61(1):55-61.

5. Lu D, Estalilla OC, Manning JT Jr, Medeiros LJ. Sinus histiocytosis with massive lymphadenopathy and malignant lymphoma involving the same lymph node: a report of four cases and review of the literature. Mod Pathol. 2000;13(4):414.

6. Luppi M, Barozzi P, Garber R, Maiorana A, Bonacorsi G, Artusi T, Trovato R, Marasca R, Torelli G. Expression of human herpesvirus- 6 antigens in benign 
and malignant lymphoproliferative diseases. Am J Pathol. 1998 Sep 1;153(3): 815-23.

7. Foucar E, Rosai J, Dorfman R. Sinus histiocytosis with massive lymphadenopathy (Rosai-Dorfman disease): review of the entity. In Seminars in diagnostic pathology 1990 Feb (Vol. 7, No. 1, pp. 19-73).

8. Rosai J. Sinus histiocytosis with massive lymphadenopathy: a newly recognized benign clinicopathological entity. Arch Pathol. 1969;87:63-70

9. Wenig BM, Abbondanzo SL, Childers EL, Kapadia SB, Heffner DR. Extranodal sinus histiocytosis with massive lymphadenopathy (Rosai-Dorfman disease) of the head and neck. Hum Pathol. 1993;24(5):483-92.

10. Snehalatha R, Senthilnathan P, PRathiba Ramani SJ. The Rosai Dorfman syndrome-the report of a rare case. J Clin Diagn Res. 2013 Jul;7(7):1519.

11. Deshpande AH, Nayak S, Munshi MM. Cytology of sinus histiocytosis with massive lymphadenopathy (Rosai-Dorfman disease). Diagn Cytopathol. 2000; 22(3):181-5.

12. Bist SS, Bisht M, Varshney S, Pathak VP. Rosai Dorfman syndrome with extranodal manifestation. Japi. 2007;55:445-7.

13. McAlister WH, Herman T, Dehner LP. Sinus histiocytosis with massive lymphadenopathy (Rosai-Dorfman disease). Pediatr Radiol. 1990 Jul 1;20(6):425-32.

14. Sugimoto K, Ueda S, Okada M, Takemura T. Membranoproliferative glomerulonephritis associated with Rosai-Dorfman disease. Clin Nephrol Case studies. 2017:5:54.

15. Foucar E, Rosai J, Dorfman RF, Eyman JM. Immunologic abnormalities and their significance in sinus histiocytosis with massive lymphadenopathy. Am J Clin Pathol. 1984;82(5):515-25.

16. Juskevicius R, Finley JL. Rosai-Dorfman disease of the parotid gland: cytologic and histopathologic findings with immunohistochemical correlation. Arch Pathol Lab Med. 2001;125(10):1348-50.

17. O'malley DP, Duong A, Barry TS, Chen S, Hibbard MK, Ferry JA, Hasserjian RP, Thompson MA, Richardson MS, Jaffe R, Sidhu JS. Co-occurrence of Langerhans cell histiocytosis and Rosai-Dorfman disease: possible relationship of two histiocytic disorders in rare cases. Mod Pathol. 2010; 23(12):1616.

18. Grabczynska SA, Toh CT, Francis N, Costello C, Bunker CB. Rosai-Dorfman disease complicated by autoimmune haemolytic anaemia: case report and review of a multisystem disease with cutaneous infiltrates. Br J Dermatol. 2001:145(2):323-6.

19. Akria L, Sonkin V, Braester A, Cohen HI, Suriu C, Polliack A. Rare coexistence of Rosai-Dorfman disease and nodal marginal zone lymphoma complicated by severe life-threatening autoimmune hemolytic anemia. Leukemia Lymphoma. 2013 Jul 1;54(7):1553-6.

20. Lardhi AA, Al-Mutairi AK, Al-Qahtani MH, Al-Mutairi AK. Rosai-Dorfman disease complicated by autoimmune hemolytic anemia in a child: a case report and review of the literature. Case Rep Oncol. 2018;11(1):55-62.

21. Rodriguez-Galindo C, Helton KJ, Sánchez ND, Rieman M, Jeng M, Wang W. Extranodal Rosai-Dorfman disease in children. J Pediatr Hematol Oncol. 2004;26(1):19-24

22. Horneff G, Jürgens H, Hort W, Karitzky D, Göbel U. Sinushistiocytosis with massive lymphadenopathy (Rosai-Dorfman disease): Response to methotrexate and mercaptopurine. Med Pediatr Oncol. 1996;27(3):187-92.

23. Alqanatish JT, Houghton K, Bond M, Senger C, Tucker LB. Rituximab treatment in a child with Rosai-Dorfman disease and systemic lupus erythematosus. J Rheumatol. 2010;37(8):1783-4.

24. Cohen-Barak E, Rozenman D, Schafer J, Krausz J, Dodiuk-Gad R, Gabriel H, Shani-Adir A. An unusual co-occurrence of Langerhans cell histiocytosis and Rosai-Dorfman disease: report of a case and review of the literature. Int J Dermatol. 2014;53(5):558-63.

25. Maia RC, de Meis E, Romano S, Dobbin JA, Klumb CE. Rosai-Dorfman disease: a report of eight cases in a tertiary care center and a review of the literature. Braz J Med Biol Res. 2015;48(1):06-12.

26. Garces S, Medeiros LJ, Patel KP, Li S, Pina-Oviedo S, Li J, Garces JC, Khoury JD, Yin CC. Mutually exclusive recurrent KRAS and MAP 2K1 mutations in Rosai-Dorfman disease. Mod Pathol. 2017;30(10):1367.

\section{Publisher's Note}

Springer Nature remains neutral with regard to jurisdictional claims in published maps and institutional affiliations.

Ready to submit your research? Choose BMC and benefit from:

- fast, convenient online submission

- thorough peer review by experienced researchers in your field

- rapid publication on acceptance

- support for research data, including large and complex data types

- gold Open Access which fosters wider collaboration and increased citations

- maximum visibility for your research: over $100 \mathrm{M}$ website views per year

At BMC, research is always in progress.

Learn more biomedcentral.com/submissions 